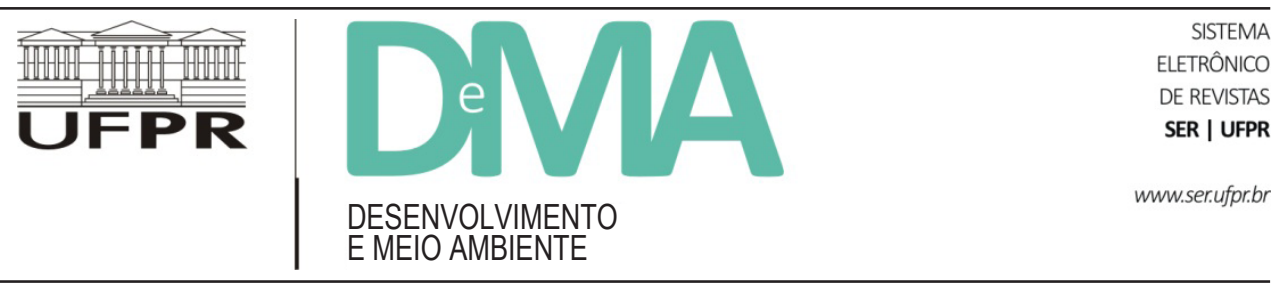

\title{
Zonas de amortecimento de Unidades de Conservação em ambientes urbanos sob a ótica territorial: reflexões, demandas e desafios
}

\section{Buffer Zones of Protected Areas in Urban Areas under the Territorial View: Reflections, Demands and Challenges}

\author{
Helio BEIROZ ${ }^{*}$ \\ ${ }^{1}$ Programa de Pós-Graduação em Geografia, Universidade Federal Fluminense (UFF), Rio de Janeiro, RJ, Brasil. \\ *E-mail de contato: beirozhelio@gmail.com
}

Artigo recebido em 14 de outubro de 2014, versão final aceita em 17 de agosto de 2015.

RESUMO: O presente artigo aborda as demandas e desafios relacionados às zonas de amortecimento de Unidades de Conservação em áreas urbanas, por meio da contextualização histórica e legal desta "ferramenta" de planejamento e gestão territorial. Foca-se sobre uma abordagem territorial de tais Zonas, tratando questões e desafios pertinentes a quaisquer unidades em áreas urbanas e aqueles específicos dos dois "Parques Urbanos" do município do Rio de Janeiro, o Parque Estadual da Pedra Branca e o Parque Nacional da Tijuca, a título de aprofundamento. Conclui-se que tais Zonas são importantíssimas para Parques envoltos por áreas urbanas, mesmo que a interação de atores e interesses, e seus consequentes reflexos territoriais, ocorram de maneira muito complexa. De fato, tal cenário reforça a necessidade dessa ferramenta como um instrumento de gestão e planejamento territorial, mitigação de conflitos e de conservação ambiental.

Palavras-chave: Unidades de Conservação; zonas de amortecimento; gestão territorial; planejamento territorial.

ABSTRACT: This article aims the demands and challenges related to the Buffer Zones of Protected Areas in urban areas, through the historical and legal contextualization of this "tool" of territorial planning and management. It focuses on a territorial approach of these Zones, addressing issues and challenges relevant to any Protected Areas in urban areas, and those specific to two "Urban Parks" in Rio de Janeiro, State Park Pedra Branca and Tijuca National Park, by deepening the analysis. We conclude that such zones are very important for Parks surrounded by urban areas, even though the interaction of actors and interests, and their consequent territorial reflexes, occur in very complex ways. In fact, such a scenario reinforces the need for this tool as a land planning and management tool, conflict mitigation and environmental conservation.

Keywords: protected areas; buffer zones; land management; land planning. 


\section{Introdução}

As Unidades de Conservação (UCs) estão entre os principais - talvez o principal - instrumentos de proteção ambiental que compõem a agenda do poder público e da sociedade civil no Brasil, com influência direta sobre a gestão e o planejamento do território. Tais áreas correspondem a recortes espaciais onde o acesso, a ocupação, o aproveitamento econômico de recursos e qualquer outro tipo de alteração por parte das atividades humanas estão limitados por normas específicas com o objetivo de garantir a conservação da qualidade ambiental dessas próprias áreas, seus entornos e, em escala mais ampla, o equilíbrio ambiental necessário às atividades econômicas e produtivas do homem. Contudo, a adequada criação, o planejamento e a gestão de tais áreas ainda se dão em um cenário marcado por embates de diversos agentes, que imprimem no território os reflexos de seus interesses políticos e econômicos. Hoje, não obstante a pertinência de tais desafios que impõem cenários muitas vezes desfavoráveis às UCs, é aceita a necessidade da criação e adequada manutenção dessas áreas.

A maior parte das pressões antrópicas sofridas por UCs é oriunda dos seus entornos. Desde o avanço de usos inadequados do solo e recursos naturais, incluindo a extração de componentes da flora e fauna e avanço de franja urbana e agropecuária, até a ocorrência de incêndios criminosos e acidentais e o despejo de elementos poluidores, entre outros, são mais comuns nas bordas das UCs. Assim, torna-se imprescindível que a criação, o planejamento e a gestão das unidades incorporem a gestão territorial das áreas a elas vizinhas. O instrumento hoje chamado de Zona de Amortecimento tem essa função e existe na legislação, sob diferentes termos, parâmetros e configurações, há mais de duas décadas e também no plano de manejo de diversas UCs.

O presente artigo aborda, sob a ótica territorial, a questão do entorno de UCs, com foco sobre aquelas localizadas em áreas urbanas, com o objetivo de oferecer uma discussão dos desafios e demandas dessas áreas. Utiliza-se como direcionamento a definição de Zona de Amortecimento trazida pelo Sistema Nacional de Unidades de Conservação - SNUC (Brasil, Lei n ${ }^{\circ}$ 9.985, de 18 de julho de 2000), porém é realizada também uma breve discussão do histórico de evolução dos instrumentos associados à gestão das áreas no entorno de UCs. Com o intuito de contextualizar e aprofundar a discussão, trata-se do cenário de duas UCs em áreas urbanas do município do Rio de Janeiro, o Parque Estadual da Pedra Branca e o Parque Nacional da Tijuca. Pretende-se, assim, colaborar com a reflexão e consequente proposição de iniciativas com vistas a favorecer a eficiência da gestão e do alcance dos objetivos de conservação ambiental das UCs.

\section{As Zonas de Amortecimento}

Segundo Perello (2012), inicialmente as Zonas de Amortecimento (ZAs) tinham como objetivo proteger a população humana dos animais selvagens que escapavam de áreas protegidas na Índia e na África. Na atualidade, a função principal das ZAs é, ironicamente e de forma quase oposta, a de proteger as unidades de conservação de impactos oriundos das atividades desenvolvidas em seu entorno. No SNUC consta que as UCs, exceto Áreas de Proteção Ambiental e Reservas Particulares do Patrimônio Natural, devem possuir uma ZA que corresponda ao "entorno de uma unidade de conservação, onde as atividades humanas estão sujeitas a normas e restrições específicas, com o propósito de minimizar os impactos negativos sobre a unidade" (SNUC, art. 2, XVIII), sendo responsabilidade do órgão responsável pela administração da unidade estabelecer normas regulamentando a ocupação e o uso dos recursos da ZA. Os limites da ZA e as respectivas normas poderão ser definidos no ato de criação da unidade ou posteriormente, compondo o plano de manejo das UCs (Brasil, 2000, art. 25, § $2^{\circ}$ ).

Segundo Ribeiro et al. (2010), a exigência do estabelecimento das ZAs foi uma vitória associada à elaboração do SNUC em 2000, momento a partir do qual, em termos normativos, as áreas do entorno das UCs também estariam sujeitas a restrições com objetivo de minimizar os impactos adversos gerados pelas pressões que se estabelecem sobre áreas protegidas. Segundo os mesmos autores, tão importante quanto gerir as UCs em si é estabelecer critérios de ocupação e monitoramento das ZAs, que serviriam também como um mecanismo 
de frenagem para o avanço de atividades incompatíveis com a conservação das UCs.

Em consonância, Perello (2012) destaca que as ZAs devem ter por objetivo "garantir a integridade dos objetivos de conservação da área protegida, complementando, ou suplementando hábitats de interesse" (Perello, 2012, p. 2). Indo além, chama a atenção para o potencial da ZA no sentido do aumento da extensão de hábitats fragmentados. Contudo, deve oferecer benefícios ambientais, sociais e econômicos às populações humanas no entorno da UC. Nesse sentido, é coerente que os órgãos responsáveis pela gestão das UCs estabeleçam, integradamente ao plano de manejo das áreas protegidas, o planejamento territorial das áreas em seus entornos, além de gozar de autoridade para autorizar, ou vetar, a instalação de empreendimentos e modificações nos padrões de uso do solo e ocupação nas ZAs, conforme previsto no SNUC (Brasil, 2000, art. 25, § $1^{\mathrm{o}}$; art 27, § $1^{\circ}$; art. $36, \S 3^{\circ}$ ). Cabe realçar, no entanto, que tal processo deve ocorrer de forma democrática e participativa, em prol do bem-estar da população local, prezando por planos e intervenções no sentido da compatibilização do modo de ocupação do entorno da UC com os objetivos dessa, sempre que possível.

O que hoje aparenta um cenário de clareza legal e normativa acerca das ZAs na verdade é oriundo de décadas de diretrizes confusas e marcadas, até mesmo, pela sobreposição de mecanismos, como era o caso do conceito de Área Circundante (AC). Segundo Maia Neto (2010):

[...] a área circundante (Resolução CONAMA n. 13/1990) e a zona de amortecimento (Lei n. 9.985/2000) são institutos jurídicos distintos e que devem ser aplicados cumulativamente, especialmente para proteger as unidades de conservação do efeito de borda. (Maia Neto, 2010, p. 3).

Em linhas gerais, a diferença entre a AC e a ZA se baseia em 3 aspectos. AAC trata do licenciamento do uso do solo, enquanto a ZA trataria da normatização e da gestão das atividades a serem desenvolvidas. $\mathrm{O}$ alcance da ZA é definido no plano de manejo da UC, enquanto a AC possuiria, em todos os casos, um alcance de $10 \mathrm{~km}$. Todas as categorias de unidade de conservação possuiriam AC por força da Resolução n 13/1990 do CONAMA; já a $Z A$ não se aplica às áreas de proteção ambiental (APAs) $e$ às reservas particulares do patrimônio natural (RPPNs), como determina o SNUC (Brasil, 2000).

Perello (2012) afirma que:

Da resolução n. 10 de 1993 podia-se depreender que a área de entorno possuía a mesma função da zona de amortecimento, porém restringia-se às áreas de cobertura vegetal contínua. No que se refere à capacidade das áreas de entorno $(10 \mathrm{~km})$ contribuírem com a mitigação de impactos, observavam-se apenas duas exigências legais: a) qualquer atividade que vinha ali se instalar deveria ter a concordância do gerente da área protegida $e, b$ ) todos os empreendimentos potencialmente impactantes deveriam passar pelo processo de licenciamento ambiental. Estas regras, em geral, resultavam em pouco efeito prático. Ou porque o gestor raramente negava a anuência ou porque desde há muito são raras as atividades isentas de licenciamento ambiental (Perello, 2012, p. 5).

De qualquer forma, tal (suposta) sobreposição de instrumentos deixa de existir a partir do estabelecimento resolução ${ }^{\circ} 428$ de 2010, por meio da qual o Conselho Nacional de Meio Ambiente (Conama, 2010) revoga a resolução $\mathrm{n}^{\circ} 13 / 1990$ e estabelece em $3 \mathrm{~km}$ a faixa correspondente à ZA, caso não haja plano de manejo contendo a delimitação precisa da mesma, nos casos de empreendimentos de significativo impacto ambiental, com fundamento em estudo de impacto ambiental e respectivo relatório de impacto ambiental (EIA/Rima). Nos casos de licenciamento ambiental de empreendimentos não sujeitos a EIA/Rima, a ZA a ser considerada para as UCs que ainda não possuem seus limites estabelecidos no plano de manejo é de $2 \mathrm{~km}$.

Em informe do Ministério do Meio Ambiente (MMA, 2010 apud Caminha, 2010) apresenta informações complementares que tornam mais urgentes as demandas pelo estabelecimento da ZA das UCs:

Os órgãos responsáveis pela administração das unidades de conservação - tanto federal quanto estaduais e municipais - têm, de acordo com a nova resolução, prazo de cinco anos contados da publicação da resolução para definir os planos de manejo das UC que ainda não os possuem. Após esse prazo, para as UC sem plano de 
manejo, a zona de amortecimento passa a não existir. [...] A regra revogada - Resolução Conama 13/1990 estabelecia que, para unidades de conservação sem plano de manejo, a zona de amortecimento seria sempre de 10 mil metros (Caminha, 2010).

Ao longo das décadas, essa área definida com vistas à proteção das áreas protegidas já sofreu outras variações. Por exemplo, pela lei n ${ }^{\circ} 5.197 / 67$, que tratava da proteção da fauna e estabelecia faixas marginais diferentes para determinadas atividades, no entorno de áreas protegidas, como, por exemplo, a proibição da caça e captura de animais silvestres a até $5 \mathrm{~km}$ de estabelecimentos oficiais e açudes públicos. Concretamente, o SNUC (2000) definiu o conceito de Zona de Amortecimento para UCs e, com a resolução n. 428 de 2010, do CONAMA, a sua regulação em situações de ausência de plano de manejo em UCs.

A diminuição da faixa da - hoje chamada - ZA acarreta a diminuição da área de amortecimento de impactos às UCs, porém, por outro lado, pode oferecer uma margem de manobra bem mais verossímil para o planejamento e manejo desses espaços em áreas com usos consolidados, em especial áreas urbanas. Tornando a tratar do aspecto negativo da redução, não é incoerente supor que a perda de área submetida à gestão da UC em seu entorno prejudica o estabelecimento de corredores ecológicos e a gestão integrada de múltiplas UCs em ambientes de grande fragmentação florestal. O que é, em geral, o caso dos fragmentos de Mata Atlântica próximos aos grandes centros urbanos (ou envolvidos por esses) ou em áreas de atividades agropecuárias consolidadas.

Calcado no exposto, a partir do momento em que se consolida tal ferramenta e são criadas normas para viabilizar sua implantação, demandam-se o aprofundamento e a diversificação das discussões - e aplicações - acerca do planejamento e gestão desses espaços. Mas, primeiramente, precisamos compreender as demandas e os desafios presentes nos contextos em que as ZAs são implantadas, para garantir sua efetiva implementação. O presente trabalho visa, mediante a análise bibliográfica, tecer algumas reflexões e levantar questões que colaborem para a compreensão do cenário atual, com ênfase sobre a situação de vizinhança às áreas urbanas, na qual se enquadram diversas UCs brasileiras, em especial aquelas em proximidade ou inseridas em áreas metropolitanas.

\section{Planejamento e ordenamento territorial de Zonas de Amortecimento em ambientes urbanos}

Segundo apontam Coelho et al., tratando de um contexto no qual que se pode incluir a questão do entorno das UCs:

\begin{abstract}
Os estudos meramente diagnósticos das unidades de conservação, mesmo quando acompanhados de esforços de zoneamento geográfico-ecológico, oferecem resultados limitados e pouco criativos, insuficientes para dar conta da complexidade de relações, processos e contradições inerentes à própria constituição das unidades de conservação e à formulação e execução das políticas ambientais/conservacionistas em geral (Coelho et al., 2009, p. 72).
\end{abstract}

O SNUC (Brasil, 2000. art. 49) determina que o interior de UCs de proteção integral é considerado, para os efeitos legais, zona rural e que as ZAs de tais UCs, quando definidas formalmente, não podem ser transformadas em zonas urbanas. Ou seja, em situações na qual se estabelece a ZA de uma unidade de conservação, aquelas áreas não podem sofrer mudanças de uso do solo que as transforme em áreas urbanas, pelo simples fato de que áreas urbanas, especialmente aquelas densamente ocupadas, representam pressões e ameaças às UCs. Tal situação pode representar a "perda" de uma grande área para expansão da malha urbana nas áreas metropolitanas.

Em adição, deve-se considerar que, no caso de UCs sem plano de manejo:

[...] todas as atividades e obras desenvolvidas nas unidades de conservação de proteção integral devem se limitar àquelas destinadas a garantir a integridade dos recursos que a unidade objetiva proteger, assegurando-se às populações tradicionais porventura residentes na área as condições e os meios necessários para a satisfação de suas necessidades materiais, sociais e culturais (Brasil, 2000, art. 28). 
Deve-se considerar também a resolução $\mathrm{n}^{\circ} 428$, de 2010, do CONAMA, anteriormente citada, que estabelece como área de amortecimento as faixas de $3 \mathrm{~km}$ para empreendimentos de impacto relevante e de $2 \mathrm{~km}$ para empreendimentos sem impacto ambiental relevante. Mas não fica claro se as ZAs, nesse caso em que não estão estabelecidas pelo plano de manejo, ficam sujeitas ao disposto no artigo 49 do SNUC, quanto à conversão em áreas urbanas. A questão é: considerando que a resolução $\mathrm{n}^{\circ} 428$ (Conama, 2010) entrou em vigor após o artigo 49 do SNUC (2000), pode-se considerar que ela formaliza a ZA, mesmo no caso de não haver plano de manejo definido? Caso a resposta seja "sim, ela formaliza", então, mesmo quando não se tem o plano de manejo das UCs, áreas das ZAs não podem ser convertidas em espaços urbanos. Se considerarmos tal perspectiva, o planejamento de ZAs, a partir de 2010, deve considerar a resolução $\mathrm{n}^{\circ}$ 428, no sentido do impedimento da expansão de áreas urbanas sobre as ZAs ou daquelas já existentes, mesmo quando o plano de manejo da área protegida não inclui o planejamento da ZA ou quando o plano de manejo não existe. Neste último caso, ou seja, na ausência de plano de manejo para a UC, torna-se incoerente, ou algo vazio, falar de planejamento da ZA.

Segundo Costa et al. (2007), o que vem ocorrendo no contexto brasileiro é que os estudos diagnósticos para criação e os esforços efetivos de manejo, em sua grande maioria, negligenciam as áreas do entorno das UCs em prol de seus interiores, quando deveriam considerar essas duas áreas como complementares para o sucesso das UCs. De uma forma geral, conforme já abordado, é de grande importância que a ZA seja planejada e gerida de maneira integrada à UC que ela "protege". Perello (2012) assinala que poucas mudanças relevantes ocorreram no quadro após levantamentos bibliográficos que incluíram exemplos de casos nacionais e internacionais e afirma que há poucos trabalhos apontando diretrizes para a demarcação e manejo de ZAs, em especial na forma de roteiros. Mas, tal quadro não se apresenta de maneira dissonante ao contexto da própria criação de unidades de conservação, ainda bastante discutida e, em alguns casos, polêmica, em geral, como aponta Vallejo (2005), por desconsiderar as territorialidades do espaço ocupado pelas UCs. Essa deficiência também inclui a ZA de tais UCs.
Segundo Primack e Rodrigues (2001), o planejamento do formato e das estratégias de manejo das UCs ainda está aquém das demandas de conservação do meio ambiente. Há que se considerar, também, que realizar o planejamento e manejo de áreas protegidas em condições ambientais e sociais tão diversificadas quanto as brasileiras impõe um desafio formidável, que dificilmente poderia ser superado com propostas e roteiros que não sejam versáteis. Não obstante, Primack \& Rodrigues (2001) destacam a importância de se buscar diretrizes simples e gerais para o planejamento de UCs, uma vez que cada situação de demanda por conservação pode ser única.

Retomando a abordagem de Vallejo (2005), cabe realçar que:

\begin{abstract}
A criação de UC tornou-se a principal resposta política dos governos às demandas de conservação da biodiversidade... [Contudo] não adianta definir materialmente o território se não houver esforço de incorporação de valores simbólicos a ele. O problema é que a construção das relações afetivas entre esses territórios e os grupamentos sociais, principalmente urbanos, não é imediata e depende da intermediação de um amplo processo educativo no qual o uso e a valorização desses espaços caminhem juntos (Vallejo, 2010, p. 53).
\end{abstract}

Isto significa que, ao se planejar o território, há que se pensar na transformação (ou incorporação) desses espaços a serem protegidos enquanto lugares de diversos grupos sociais. Há que se compreender e considerar no planejamento que os lugares são dinâmicos e influenciam diretamente na construção e na desconstrução da ordem territorial. A compreensão do lugar significa "compreender uma relação possível entre questões políticas e econômicas e teias de significações e vivências expressas localmente" (Ferreira, 2000, p. 81), sem que se perca de vista as outras escalas de estruturas envolvidas.

O planejamento territorial de UCs e seus entornos deve favorecer ao ordenamento segundo os ideais de conservação e os objetivos da área protegida. Contudo, a partir da análise das diversas obras citadas no presente trabalho, apresenta-se um quadro de relevante negligência quanto ao caráter dinâmico do ordenamento, como se o arranjo espacial das atividades, valores e funções 
que convergem para um determinado fim e orientam as transformações espaciais - uma das interpretações de ordem territorial (Soares, 2009) - fosse cristalizado pelos objetivos do planejamento ou pela simples criação de uma área protegida, sem o devido plano de manejo situação ainda mais grave. Soares (2009) chama atenção para o fato de a ordem territorial não ser uma construção rígida, mas sim um cenário dinâmico, onde a ordem e a desordem - no sentido da crise da ordem vigente e sua reestruturação em um cenário que pode ser diferente do anterior, passando por um período de transição, em muitos casos, turbulento - se sucedem em consequência de diversos fatores de âmbitos político, econômico, produtivo, social, cultural e ambiental.

Coelho et al. (2009) aproximam-se de Vallejo (2005) no que tange à relação entre a população e as UCs e a Soares (2009) no que tange à questão do ordenamento territorial:

As unidades de conservação são tanto fatos concretos quanto paradigmas (conjuntos de ideias sobre as formas apropriadas de conservar/preservar a natureza), lócus de práticas sociais e de exercício de poder (relações de poder e de controle territorial); e também instituições que buscam regular comportamentos e organizar as relações sociais. Mas que são elas próprias (unidades de conservação entendidas em termos institucionais) influenciadas pelas práticas institucionalizadas dos agentes sociais e pelas disputas entre eles (Coelho et al., 2009, p. 73).

Segundo a definição de Marcelo Souza, "O Território é, fundamentalmente, um espaço que se define e é delimitado por e a partir de relações de poder" (Souza, 2006, p. 78). Na mesma obra, o autor aponta que aspectos como o acesso a recursos naturais, as características geológicas e geomorfológicas, o que se produz e quem produz em um determinado espaço, além dos laços afetivos, culturais ou de identidade com uma determinada área são fatores inerentes aos embates entre os atores que almejam o controle do território. Contudo, traz a reflexão de que ainda mais relevante - ou ao menos a ser tomada em ordem prévia, ao se tratar o planejamento e o ordenamento do território - é a questão de "quem domina ou influencia esse espaço?” (Souza, 2006, p. 79).
Seguindo por essa linha de raciocínio, podemos gerar interessantes reflexões acerca das ZAs das UCs, tão problemáticas e, na maioria dos casos, (ainda?) aquém do potencial de desempenhar sua função de mitigar as pressões sobre as áreas protegidas. Calcado em Harvey (1996), Soares (2009) nos permite chegar à reflexão de que o planejamento e a gestão do território podem ser contemplados pelo (e, também, contemplar o) ordenamento do mesmo. Porém, o ordenamento vai além dos planos de estruturas e grupos específicos, uma vez que a capacidade de organizar o espaço por meio da constituição e dinâmica de um recorte territorial "advém de todo um complexo de forças mobilizadas por diversos agentes sociais" (Harvey, 1996), sendo esse cenário mais complexo e conflituoso conforme mais variados são os atores envolvidos no ordenamento de um território. Situação essa que impõe grandes desafios à gestão e ao planejamento de áreas protegidas, especialmente em ambientes onde atores sociais se sucedem de maneira tão dinâmica, espacial e cronologicamente, como é o caso das áreas urbanas. Se consideramos que a eficiência do planejamento territorial da ZA depende da implementação da "manifestação" do ordenamento desejado, é indispensável que se avaliem quais os atores envolvidos e de que maneira eles se envolvem. De que forma se apresentam as relações de poder ou de acesso ao grupo que detém o poder? De que forma os grupos (ou atores) interferem e planejam a configuração dos recortes espaciais a serem estabelecidos com vistas à conservação ambiental?

Segundo Primack e Rodrigues (2001), “a aquisição de terras [para a criação de UC] é, na grande maioria das vezes, muito mais uma questão de oportunidade do que uma questão de completar um padrão geométrico" (Primack \& Rodrigues, 2001, p. 229) adequado às propostas vigentes de planejamento e ordenamento. Complementarmente, interpretemos o exposto anteriormente à luz do que nos apontam Castro Júnior (2009) e Medeiros (2003), quando afirmam que grande parte das UCs é criada, apesar das diversas ferramentas institucionais atuais voltadas à questão ambiental, não para proteger paisagens de um futuro impacto, mas sim em áreas que já apresentam conflitos territoriais, fundiários e de acesso a recursos, em geral já causadores de impactos 
sobre o bioma. Tal contexto ocasiona sérios desafios ao planejamento e gestão das ZAs.

Se tais aspectos são fatos concretos para as UCs, não há por que julgar que seriam menos relevantes para o entorno das áreas protegidas. Afinal de contas, ao se estabelecer uma UC para proteger uma área de interesse à conservação que já sofre pressões e com conflitos, pode-se estar, automaticamente, criando uma ilha de proteção envolvida pelos próprios problemas que fomentaram sua criação. Problemas esses que evidenciam a fragilidade do planejamento e da gestão, tanto das UCs quanto de suas ZAs, e, como consequência, que o ordenamento territorial resultante não colaborará com os ideais de conservação, tendo em vista a direção predominante das pressões que ocorrem sobre as UCs.

A tendência é sempre ocorrer pressões de fora para dentro da unidade, particularmente da população, no sentido de avançar para novas áreas, na medida em que o entorno for se tornando saturado, como é o caso das baixadas litorâneas e interioranas que margeiam as áreas protegidas dos maciços litorâneos da cidade do Rio de Janeiro (Costa et al., 2007, p. 16).

Há de se considerar as transformações que ocorreram sobre tais áreas, o processo de ocupação, as mudanças na configuração do uso do solo e as tendências atuais para que se possa mitigar as atuais pressões e impactos e prevenir os futuros. Moura \& Costa (2009), ao tratar dos desafios de gestão do Parque Estadual da Pedra Branca, unidade de conservação localizada no município do Rio de Janeiro, que é vizinha tanto de áreas densamente urbanizadas como de áreas periurbanas com características típicas de áreas agrícolas vizinhas a centros urbanos, apontam impactos e pressões oriundos dos processos de ocupação - alguns recentes, outros mais remotos. Diversas pressões que se originam nas áreas no entorno da UC em questão seriam oriundas da ausência de planejamento adequado do uso e cobertura do solo no entorno, ocasionando ocupações irregulares ou, mesmo quando regulares - como alguns condomínios de classe média, média alta -, inadequadas.

Além disso, as atividades agropecuárias, especialmente em uma das vertentes do maciço parcialmente protegido pela UC, avançam sobre áreas de floresta secundária. As informações apresentadas pelos autores denotam que os processos que geraram essas e outras pressões ao parque não são recentes, mas assumiram maior relevância mediante o aumento da especulação imobiliária e o adensamento urbano do entorno, causando impactos diretos e indiretos à UC, além da ascensão do risco ambiental à população, em função da fragilização das encostas pela alteração de suas características geomorfológicas e de cobertura vegetal. Tem-se, em adição a tal cenário, a sucessão de políticas públicas que, salvo raras exceções, deixaram em segundo plano as preocupações com a conservação ambiental. Em linhas gerais, destaca-se que a sucessão histórica de usos, funções e interesses dos atores locais e regionais teve um papel central para a constituição do atual quadro da UC e seu entorno.

Corroborando a abordagem dos poderes por detrás dos arranjos territoriais frente à questão ambiental - embora, em uma abordagem mais ampla e não especificamente das áreas protegidas -, Acselrad (2004) aponta que muitos dos embates recorrentes nas cidades nas últimas décadas, relacionados a conflitos de uso de solo e conflitos ambientais, seriam gerados por reações de defesa da qualidade de vida, ameaçada por avanços (espaciais e políticos) do modelo econômico vigente, e pela negligência das necessidades socioambientais das populações de menor poder aquisitivo, ou sem representação política. Trazendo o enfoque especificamente sobre as ZAs em áreas urbanas, Dios \& Marçal (2009) destacam que UCs criadas em tal contexto atingem diretamente as atividades econômicas locais, sendo importante considerar tais impactos no planejamento da área ao seu entorno, o que leva os autores a concluir, em uníssono com as demais abordagens tratadas, que a gestão, o planejamento das atividades e a ocupação da ZA devem ser realizados em coerência com a gestão da UC que ela protege.

\section{Reflexões acerca de atores, demandas, disputas e pressões sobre os parques do município do Rio de Janeiro}

Chega-se então à conclusão de que é imprescindível que as áreas urbanas que efetuam pressões sobre 
as UCs sejam abrangidas pelo planejamento de uso e cobertura do solo. Ilustrando uma alternativa, muito embora supostamente não a única, cita-se o fato de que o Plano Diretor do Município do Rio de Janeiro (Rio de Janeiro, 2011) define, enquanto UC de uso sustentável, a categoria Área de Proteção Ambiental e Regulamentação Urbana (APARU) que, segundo o texto da Lei Complementar $\mathrm{n}^{\circ} 111$, no artigo 110 , parágrafo $3^{\circ}$, inciso III, é "de domínio público ou privado [...] e depende de ações do Poder Público para a regulação do uso e ocupação do solo e restauração de suas condições ecológicas e urbanas". Tem-se, assim, uma UC na qual dentre os objetivos principais consta a recuperação urbana, que pode ser entendida como a melhoria da qualidade de vida da população, o que, consensualmente, inclui melhoria da qualidade ambiental. No parágrafo único do artigo 111 do mesmo Plano Diretor, consta que as APARUs podem coexistir com outras UCs, o que - juntamente com a possibilidade de cobrir áreas urbanas - abre margem ao uso dessa categoria como um instrumento semelhante à zona de amortecimento, no caso de áreas urbanas consolidadas no entorno de outras UCs. Cabe destacar que a categoria APARU não é criada na Lei Complementar $n^{\circ} 111$, mas já constava em versões anteriores do Plano Diretor do Município do Rio de Janeiro (Rio de Janeiro, 1992).

Tal estratégia é utilizada para a proposta de zoneamento abordada por Oliveira \& Santos (2004), que teve como base o trabalho do Laboratório de Geohidroecologia da Universidade Federal do Rio de Janeiro GEOHECO (2003) - da APARU do Alto da Boa Vista, que se encontra parcialmente sobreposta ao Parque Nacional da Floresta da Tijuca (PNT). A APARU em questão contempla, dentre seus objetivos, a revitalização urbana em consonância com os condicionantes geobiofísicos da área. Tal exemplo é apenas uma ilustração das possibilidades de tratar das questões dos entornos urbanizados das UCs do município do Rio de Janeiro, mas supõe-se que não seja a única alternativa, apesar de apresentar significativa viabilidade, posto que tem como premissa "promover a recuperação urbana e preservar o patrimônio natural de forma compatível com a história e desenvolvimento da cidade construída pelo homem" (Oliveira \& Santos, 2004, p. 6).

Não obstante, o trabalho tem o mérito de apontar algumas medidas/intervenções relevantes à problemá- tica da urbanização densa no entorno de UCs, como a excessiva pavimentação, a diminuição da arborização, as mudanças no escoamento superficial hídrico e de sedimentos, a relação entre a área construída dos lotes e suas áreas totais, etc. Só o tempo poderá ilustrar os resultados da intervenção em longo prazo - considerando que o Poder Público cumpra o seu papel na adequação da área às demandas da proposta -, mas, acima de tudo, o exemplo demonstra que é viável pensar na adequação da cidade à floresta, sem que uma das duas deixe necessariamente de existir. Em áreas urbanas, a pressão imobiliária e o avanço de áreas de ocupação irregular são problemas comuns que, em geral, manifestam-se primeiro sobre as ZAs das áreas protegidas e avançam sobre as mesmas.

Tratando do exemplo de outra UC do município do Rio de Janeiro, Vallejo et al. (2009) apontam que, no Parque Estadual da Pedra Branca (PEPB), tais fontes de pressão têm um papel central enquanto fonte de conflito com os ideais de preservação da unidade. No contexto da UC em questão, segundo os autores, novas frentes de avanço da especulação imobiliária somam-se com áreas envolvidas em conflitos antigos, relacionados a ocupações legais e ilegais, principalmente na forma de invasões.

Destacam-se ainda, como ocorrência frequente no PEPB, os incêndios, muitos deles diretamente relacionados à ação antrópica, como destacam, mais recentemente, Brandão \& Miranda (2012). Segundo os mesmos autores, há correlação entre o avanço da ocupação irregular e o número de incêndios na UC, potencializado por condições climáticas e geográficas em algumas das vertentes do maciço que compõem o Parque. Entre essas condições, os autores destacam a baixa umidade do solo e altas temperaturas na vertente Norte - em especial nos arredores do bairro de Bangu - fora dos meses mais chuvosos. Destacam ainda que $\mathrm{a}$ área de Bangu e arredores possui deficiência hídrica moderada no verão e os avanços da população têm um papel nítido na substituição da vegetação nativa - já menos densa em tal vertente - por gramíneas com alto potencial de combustibilidade.

Ainda associados diretamente às pressões do avanço da ocupação antrópica, especialmente residencial, em direção ao PEPB, Vallejo et al. (2009) apontam o impacto causado por esgoto e lixo como o segundo mais relevante 
documentado na UC (ocupação irregular e fogo empatam em primeiro lugar - $30 \%$ das ocorrências). Os impactos são seguidos pelo corte de vegetação, pelas atividades de mineração, agricultura e pecuária e faixas de servidão e torres de transmissão.

Quanto à gravidade das atividades de mineração no PEPB frente à gestão das áreas da UC e entorno, cabe citar a denúncia realizada na página on-line mantida por voluntários que atuam na conservação do Parque:

Mais grave ainda é o problema das pedreiras, sobretudo as de granito ornamental, que vêm degradando o Maciço da Pedra Branca. Essa exploração ocorre de maneira tão rápida, que o Poder Público não tem tempo de embargar. O simples embargo não tem se mostrado eficaz, pois, na maioria das vezes, ou a atividade prossegue de forma clandestina ou é abandonada, restando um ambiente degradado e de difícil recuperação (Amigos do Parque, 2010).

Retornando à abordagem da questão em uma escala municipal, cabe destacar que tais fontes de impacto relacionadas à ocupação na área de entorno também possuem relevância no PNT, estando relacionadas ao processo de ocupação e aos tipos de cobertura em seu entorno. A coincidência é tamanha que cabe destacar um trecho do trabalho de Fernandes \& Coelho Netto (1999 apud Coelho Netto, 2005).

Podemos destacar como principais causas da devastação florestal: 1. o avanço desordenado da ocupação humana sobre as encostas, especialmente as íngremes e acima da cota altimétrica de $100 \mathrm{~m}$; 2. os incêndios florestais, detonados principalmente pela queima induzida de lixo nas favelas, ou pela queima induzida de gramíneas, ou, ainda, por balões de fogo e velas de macumba; vale comentar que esses casos agravam-se na vertente norte do Maciço e no meio do ano, onde e quando a umidade ambiental decresce acentuadamente (Fernandes \& Coelho Netto, 2005, p. 55).

Tratando ainda das pressões sobre a UC, porém sob a ótica das transformações frente ao embate entre os atores que colaboraram (e ainda colaboram em diversos casos) para o aumento das pressões sobre o PNT, Fernandes e Coelho Netto (2005) afirmam que:
[...] ressalta-se a existência de vários conflitos de interesses sócio-econômicos [sic] e políticos sobre essas áreas do Maciço da Tijuca. De um lado os proprietários querendo vender suas terras, como alternativa à estagnação econômica, ao aumento da violência urbana e aos altos impostos territoriais; assim, junto com as empreiteiras da construção civil e empresas imobiliárias, pressionam o poder público por uma revisão urgente na legislação que restringe a ocupação dessas encostas. Do outro lado, a ocupação irregular intensifica-se cada vez mais, inclusive sobre áreas de alto risco (Fernandes \& Coelho Netto, 2005, p. 55).

Na Figura 1 estão destacadas as localizações das duas UCs abordadas. Ambas se localizam próximas ao litoral fluminense, na mesorregião Metropolitana do Rio de Janeiro, entre as Baías de Sepetiba e da Guanabara. Apesar de possuir áreas caracterizadas por atividades de agropecuária, o município do Rio de Janeiro, onde estão ambos os Parques, não possui área rural, de acordo com o seu Plano Diretor Municipal. Tal fator intensifica a fragilidade das UCs às pressões ao seu redor, pois submete seus entornos a normas de ocupação e uso do solo menos restritivas, características de áreas urbanas.

Além de uma semelhança de contextos naturais e sociais, ao menos em uma escala que nos ofereça um panorama geral, as principais pressões sofridas pelos dois principais Parques do município do Rio de Janeiro têm em comum a relação direta entre a configuração de seus entornos e os agentes que atuam e interferem nas dinâmicas dessas áreas com os impactos nas UCs. Tal panorama, mais do que uma mera constatação, supostamente trivial, é um fato que aponta para a necessidade emergencial do planejamento e do ordenamento territorial das ZAs dessas áreas protegidas que encontram-se envoltas por áreas urbanas e ainda, regular ou irregularmente, em expansão.

Nem o PNT e nem o PEPB contam com um Plano de Manejo que contemple adequadamente suas ZAs, apesar de o plano de manejo do PNT (ICMBio, 2008) fazer menção à mesma, afirmando inclusive que, em função do padrão de ocupação do entorno do Parque, as possibilidades de implementação de uma ZA adequada ficariam muito restritas em extensão, longe do que determinava a Resolução CONAMA 13/1990 (faixa de 10 km a partir dos limites da UC), estabelecendo que ela fosse avaliada posteriormente à geração e à implantação do 


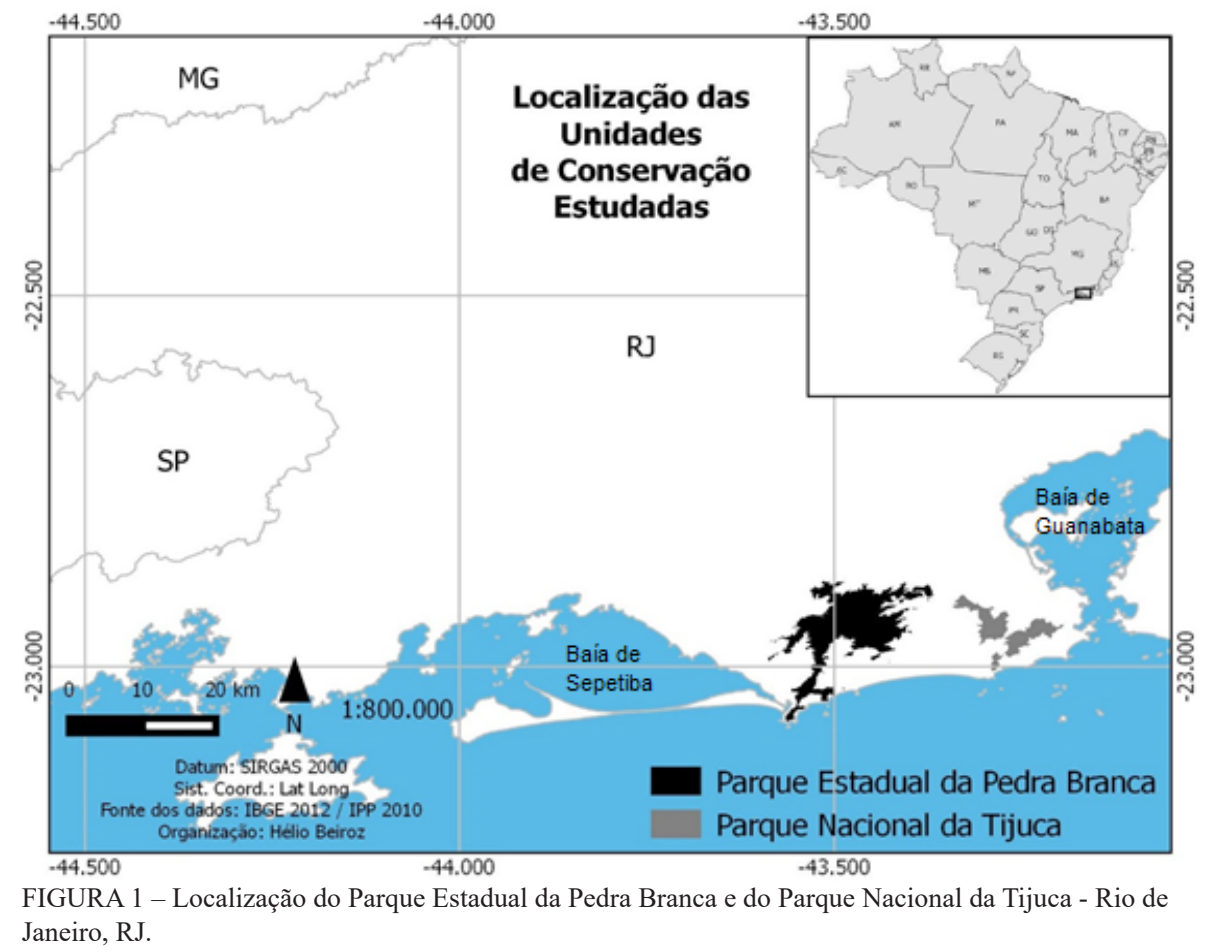

plano de manejo para o interior da UC. O PEPB ainda não conta com plano de manejo - em fase de finalização, segundo informações do Instituto Estadual do Ambiente (INEA), apesar de passados mais de 35 anos da data de sua criação.

Tal cenário coloca a conservação das áreas no entorno dos Parques em xeque frente às mais recentes transformações em seus entornos. Como exemplos de transformações ocorridas ou em andamento, temos a expansão da ocupação na forma de condomínios de "classes" alta e média alta na Barra da Tijuca e Recreio dos Bandeirantes, a instalação de novos empreendimentos de grande porte na Zona Oeste, as grandes obras rodoviárias, com efeitos principalmente sobre o PEPB e sua ZA. Mais relevantes para os impactos sobre o entorno do PNT há as transformações nas atividades e no fluxo de pessoas nas áreas recentemente pacificadas, o aumento da especulação imobiliária e as transformações de espaços públicos na Zona Sul da cidade.

Além desses fatores - embora não desarticulado deles - há que se (re)pensar o papel das áreas do entorno

das UCs frente à qualidade de vida e proteção a riscos ambientais da população das áreas urbanas ou de periferias urbanas do Rio de Janeiro, ou de qualquer outro centro urbano que englobe UCs de proteção integral, pensando-as como um campo de encontro (e embate) de interesses de diferentes atores que agem ativamente sobre a construção dos territórios.

\section{Reflexões finais}

Apesar dos diversos avanços recentes nos âmbitos legislativo e normativo, pode-se concluir, a partir das discussões estabelecidas, que o planejamento e a gestão das ZAs não se apresentam, ainda, como realidades difundidas a ponto de colaborar de maneira relevante para a conservação ambiental. As demandas pelo planejamento e pelo ordenamento territorial das áreas no entorno das UCs, em especial as de proteção integral, é latente, frente aos conflitos territoriais, fundiários e de uso do solo existentes em tais áreas. Esses fatores 
originam pressões e impactos que dificultam o manejo e o alcance dos objetivos das UCs que foram alvo do presente trabalho. A integração do planejamento do uso e manejo das áreas protegidas em questão tende a não se dar de maneira integrada às de seu entorno, o que tem reflexos negativos sobre a qualidade do manejo da própria área protegida e sobre as condições sociais e econômicas das populações vizinhas.

Em especial em ambientes urbanos, como o do município do Rio de Janeiro, tais fatores adquirem maior complexidade frente ao dinamismo de atores e interesses que se imprime sobre a organização e gestão territorial. Salvo a evidente dificuldade de compatibilização da ocupação urbana com os ideais de conservação e as premissas de uma ZA, a intensificação do uso urbano do solo no entorno das áreas protegidas tem como consequência a intensificação de diversos impactos e distúrbios ambientais aos quais as áreas protegidas naturalmente já estivessem suscetíveis em função de suas características geomorfológicas e/ou climáticas.

\section{Referências}

Acselrad, H. Desregulamentação, contradições espaciais e sustentabilidade urbana. Revista Paranaense de Desenvolvimento, 107, 25-28, 2004. Disponível em: <http://www.ipardes.gov.br/ pdf/revista_PR/107/henri.pdf $>$.

Amigos do Parque. Estado de Preservação, 2010. Disponível $\mathrm{em}:<\mathrm{http}: / /$ www.parquepedrabranca.com/p/estado-de-preservacao.html>. Acesso em: maio 2015.

Brasil. Lei no 9.985, de 18 de julho de 2000. Regulamenta o art. $225, \S 1^{\circ}$, incisos I, II, III e VII da Constituição Federal, institui o Sistema Nacional de Unidades de Conservação da Natureza e dá outras providências. Brasília: DOU de 19/07/2000.

Brandão, C. B.; Miranda, R. A. C. Relações entre elementos climáticos e geográficos nas ocorrências de incêndio florestal no Parque Estadual da Pedra Branca-RJ. Revista Brasileira de Climatologia, 8(10), 2012. Disponível em: <http://ojs.c3sl.ufpr. br/ojs/index.php/revistaabclima/article/view/30597>.

Caminha, A. F. CONAMA define zona de amortecimento de UC sem plano de manejo. MMA - Ministério do Meio Ambiente, 2010. Disponível em: <http://www.mma.gov.br/informma/ item/6717-conama-define-zona-de-amortecimento-de-uc-sem-plano-de-manejo>. Acesso em: maio 2013.
É de suma importância que se abordem as ZAs sob uma perspectiva que permita compreender e considerar os atores e as disputas que se embatem, os interesses que os movem e de que forma colaboram para a construção e a desconstrução da ordem territorial que se estabelece. Só assim serão possíveis um planejamento e uma gestão que arquem com a dinâmica das transformações desses espaços no entorno do PEPB e PNT, considerando suas inserções na dinâmica das cidades e metrópoles. Tais ambientes, em geral, favorecem a fragmentação de hábitats e a intensificação de impactos sobre as UCs, que em alguns casos representam, também, um horizonte de expansão para a ocupação residencial - muitas vezes inadequada, porém nem sempre irregular - e para algumas atividades econômicas e produtivas, posto que outras áreas possam estar saturadas, não apresentar amenidades ambientais, impor alto custo de vida ou não oferecer proximidade a recursos necessários a determinadas atividades.

Castro Junior, E.; Coutinho, B. H.; Freitas, L. E. Gestão da biodiversidade e áreas protegidas. In: Guerra, A. J. T.; Coelho, M. C. N. (Orgs.). Unidades de Conservação: abordagens e características geográficas. Rio de Janeiro: Bertrand Brasil, 2009.

Coelho, M.; Cunha, L.; Monteiro, M. Unidades de Conservação: populações, recursos e territórios. Abordagens da Geografia e da Ecologia Política. In: Guerra, A. J. T.; Coelho, M. C. N. (Orgs.). Unidades de Conservação: abordagens e características geográficas. Rio de Janeiro: Bertrand Brasil, 2009.

Coelho Netto, A. L. A interface florestal-urbana e os desastres naturais relacionados à água no Maciço da Tijuca: desafios ao planejamento urbano numa perspectiva socioambiental. Revista do Departamento de Geografia, 16, 2005. Disponível em: <http://www.revistas.usp.br/rdg/article/view/47284>.

CONAMA - Conselho Nacional do Meio Ambiente. Resolução $n^{\circ} 13$, de 06 de dezembro de 1990.

CONAMA - Conselho Nacional do Meio Ambiente. Resolução $n^{\circ} 428$, de 17 de dezembro de 2010.

Costa, N. M. C.; Costa, V. C.; Valim, C. B.; Souza, A. C. C. C.; Sales, A. C. de G. Significado e importância da zona de 
amortecimento de unidades de conservação urbanas: o exemplo do entorno das áreas legalmente protegidas da cidade do Rio de Janeiro. Revista Geo UERJ, 1(17), 2007. Disponível em: $<$ http://www.e-publicacoes.uerj.br/index.php/geouerj/article/ view/1298>.

Dios, C.; Marçal, M. Legislação ambiental e a gestão de Unidades de Conservação: o caso do Parque Nacional da Restinga de Jurubatiba-RJ. In: Guerra, A. J. T.; Coelho, M. C. N. (Orgs.). Unidades de Conservação: abordagens e características geográficas. Rio de Janeiro: Bertrand Brasil, 2009.

Fernandes, M.; Coelho Netto, A L. Análise dos principais vetores de transformação do Maciço da Tijuca (RJ) e suas influências na Dinâmica do Uso e Cobertura do Solo. Revista de Pós-Graduação em Geografia da UFRJ, 3, 147-160, 1999. Disponível em: <http://ppegeo.igc.usp.br/scielo.php?pid=S0101$-97591999000100003 \&$ script $=$ sci_arttext $>$.

Ferreira, L. F. Acepções recentes do conceito de lugar e sua importância para o mundo contemporâneo. Revista Território, 5(9), 65-83, 2000. Disponível em: $<$ http://www.revistaterritorio.com.br/pdf/09_5_ferreira.pdf $>$.

GEOHECO - Laboratório de Geohidroecologia da Universidade Federal do Rio de Janeiro; SMAC-RJ - Secretaria Municipal do Meio Ambiente do Município do Rio de Janeiro. Estudos de qualidade ambiental do geoecossistema do Maciço da Tijuca: subsídios para regulamentação da APARU do Alto da Boa Vista. Rio de Janeiro: Secretaria Municipal do Meio Ambiente, 2003.

Harvey, D. Do gerenciamento ao empresariamento: a transformação da administração urbana no capitalismo tardio. Espaço \& Debates: Revista de Estudos Regionais e Urbanos, 39, 48-64, 1996. Disponível em: <http://disciplinas.stoa.usp.br/pluginfile. $\mathrm{php} / 126423 / \mathrm{mod}$ _resource/content/1/Harvey_Do\%20gerenciamento\%20ao\%20empresariamento.pdf $>$.

ICMBio - Instituto Chico Mendes de Conservação da Biodiversidade. Plano de manejo para o Parque Nacional da Tijuca. Rio de Janeiro: DIREP/ICMBio, 2008.

Maia Neto, G. de A. Área circundante e zona de amortecimento das unidades de conservação da natureza. Institutos jurídicos distintos? Jus Navigandi, 14, 2518, 2010. Disponível em: $<$ http:/jus.com.br/artigos/14899/area-circundante-e-zona-de-amortecimento-das-unidades-de-conservacao-da-natureza $>$.

Medeiros, R. A proteção da natureza: das estratégias internacionais e nacionais às demandas locais. Rio de Janeiro, Tese (Doutorado em Geografia) - UFRJ/PPG, 2003.
Moura, J. R. S.; Costa, V. C. Parque Estadual da Pedra Branca: o desafio da gestão de uma unidade de conservação em área urbana. In: Guerra, A. J. T.; Coelho, M. C. N. (Orgs.). Unidades de conservação: abordagens e características geográficas. Rio de Janeiro: Bertrand Brasil, 2009.

Oliveira, C.; Santos, C. Florestas urbanas: normas de uso e ocupação do solo para proteção de unidades de conservação nas cidades. In: Anais do IV CBUC - Congresso Brasileiro de Unidades de Conservação. Curitiba, outubro, 2004.

Perello, L. F. C. Princípios ecológicos, legais e metodológicos do planejamento de Zonas de Amortecimento. In: Anais do VII CBUC-Congresso Brasileiro de Unidades de Conservação. Natal, outubro, 2012.

Primack, R. B.; Rodrigues, E. Biologia da conservação. Londrina: E. Rodrigues, 2001.

Ribeiro, M. F.; Freitas, M. A. V. de; Costa, V. C. O desafio da gestão ambiental de zonas de amortecimento de unidades de conservação. In: Anais do VI Seminário Latino-Americano de Geografia Física/II Seminário Ibero-Americano de Geografia Física. Coimbra, maio, 2010.

Rio de Janeiro. Lei Complementar $n^{\circ}$ 16, de 4 de junho de 1992. Dispõe sobre a política urbana do município, institui o Plano Diretor Decenal da Cidade do Rio de Janeiro, e dá outras providências. Rio de Janeiro: DCM de 09/06/1992.

Rio de Janeiro. Lei Complementar $n^{\circ} 111$, de 1 de Fevereiro de 2011. Rio de Janeiro: Diário Oficial do Rio de Janeiro de 12/04/2011.

Soares, L. A. A. O enfoque sociológico e da teoria econômica no ordenamento territorial. In: Almeida, F. G.; Soares, L. A. A. Ordenamento territorial: coletânea de textos com diferentes abordagens no contexto brasileiro. Rio de Janeiro: Bertrand Brasil, 2009.

Souza, M. J. L. de. O território: sobre espaço e poder, autonomia e desenvolvimento. In: Castro, I.; Gomes, P.; Corrêa, R. (Orgs.). Geografia: conceitos e temas. 8. ed. Rio de Janeiro: Bertrand Brasil, 2006.

Vallejo, L.R. Políticas públicas e conservação ambiental: territorialidades em conflito nos parques estaduais da Ilha Grande, da Serra da Tiririca e do Desengano (RJ). Niterói, Tese (Doutorado em Geografia) - PosGEO/UFF, 2005.

Vallejo, L. R.; Campos, R. M.; Santos Júnior, W. M. Contribuição ao estudo dos conflitos territoriais no Parque Estadual da Pedra Branca. In: Anais do I Encontro Científico Parque Estadual da Pedra Branca. Rio de Janeiro, outubro, 2009. 